\title{
Let's Find the Evidence: An Analogue Study of Confirmation Bias in Criminal Investigations
}

\author{
ERIC RASSIN* , ANITA EERLAND and ILSE KUIJPERS \\ Faculty of Social Sciences, Institute of Psychology, Erasmus University Rotterdam, \\ The Netherlands
}

\begin{abstract}
People involved in criminal proceedings (e.g. police officers, district attorneys, judges, and jury members) may run the risk of developing confirmation bias, or tunnel vision. That is, these parties may readily become convinced that the suspect is guilty, and may then no longer be open to alternative scenarios in which the suspect is actually innocent. This may be reflected in a preference for guilt-confirming investigation endeavours, as opposed to investigations that are aimed at confirming, or even excluding, alternative scenarios. In three studies, participants read a case file, and were subsequently instructed to select additional police investigations. Some of these additional endeavours were guiltconfirming (i.e. incriminating), whereas others were disconfirming (i.e. exonerating). Results suggest that additional investigation search was guided by an initial assessment of the suspect's guilt (Study 1). Furthermore, participants' tendency to select incriminating investigations increased with increased crime severity, and with the strength of the evidence present in the case file. Finally, the selection of incriminating investigations was associated with conviction rates (Study 3). However, in general, participants did not favour incriminating endeavours. That is, in the three studies, the percentages of selected incriminating endeavours did hardly or not exceed 50\%. Copyright (C) 2010 John Wiley \& Sons, Ltd.
\end{abstract}

Key words: confirmation bias; tunnel vision; criminal investigation; decision making

\section{INTRODUCTION}

Empirical research has yielded an overwhelming amount of data suggesting that people tend to test hypotheses by looking for confirmation rather than by searching for falsification. In the words of Kassin (2005): 'a warehouse of psychology research suggests that once people form an impression, they unwittingly seek, interpret, and create behavioral data that verify it' (p. 219). Or, as Nickerson (1998) puts it: 'if one were to attempt to

\footnotetext{
*Correspondence to: Eric Rassin, Faculty of Social Sciences, Institute of Psychology, Erasmus University Rotterdam, P.O. Box 1738, 3000 DR Rotterdam, The Netherlands.

E-mail: rassin@fsw.eur.nl
} 
identify a single problematic aspect of human reasoning that deserves attention above all others, the confirmation bias would have to be among the candidates for consideration' (p. 175).

Indeed, in Nickerson's (1998) analysis, confirmation bias consists of several distinct, yet related, manifestations. For one thing, confirmation bias leads people to selectively attend to information that is congruent with their prior conviction. In a classic study, Lord, Ross, and Lepper (1979) selected 24 students who were in favour of the death penalty and 24 who were against it. These participants were exposed to a number of short research reports. The reports were fabricated for this study in a way that they were all of equal quality. Some of the reports produced results supporting the crime reducing effect of death penalties, whereas others produced opposing findings. Participants were instructed to rate the quality of all research reports. Indeed, participants rated reports producing results in line with their personal opinion to be better than those describing conflicting findings. In addition, at the end of this study, participants were even more pronounced in their opinion compared with the beginning of the experiment.

Even if there is no prior personally relevant reason to confirm a hypothesis, people seem to favour confirmation as the default testing strategy. This is illustrated by Wason's card selection paradigm in which the participant has to determine whether or not four cards comply with a rule. For example, the participant is instructed that four cards have a number on one side, and a letter on the other. The pertinent rule is that if there is a vowel on one side, then there must be an even number on the other. The following cards are then presented: A, K, 4, and 7. The participant is instructed to turn over as few cards as possible in order to test whether or not the rule applies to the set of cards. The correct solution to this problem is that the A and the 7 must be turned. Strikingly, a vast majority of participants fails to turn the 7, while turning that card offers the opportunity to falsify the rule (by finding a vowel on the backside; Wason, 1968).

A final manifestation of the confirmation bias is that people even play an active role in the production of confirming information. That is, they not only attend selectively to confirming evidence, and overweigh confirming evidence, but they even create search strategies in a way that confirmation is given more opportunity than falsification. Put simply, we ask just those questions that are likely to confirm our hypothesis. Snyder and Swann (1978) gave participants a description of an extravert, and told them that they were to interview someone, and had to find out whether that person was an extravert. They were to select 12 questions to be asked during the interview, from a set of 26. Eleven items in this pool were framed in the direction of extraversion (e.g. 'What would you do if you wanted to liven things up at a party?'), 10 were framed towards introversion (e.g. 'What things do you dislike about loud parties?'), and five were irrelevant (e.g. 'What are your career goals?'). Results indicated that participants chose significantly more confirming questions, that is questions framed in the direction of extraversion $(M=4.31)$ than disconfirming (i.e. introversion-directed, $\mathrm{M}=2.46$ ) and irrelevant $(\mathrm{M}=2.24)$ questions. More strikingly, in a second study, naïve judges who evaluated the video recordings of the interviews, were actually influenced by the number of confirming questions. That is, the more confirming questions the interviewer asked, the more likely naïve judges were to perceive the interviewee as an extravert. Hence, by asking confirmatory questions, people can actually create confirmatory behavioural information, even in the eye of the naïve beholder.

There is some reason to argue that the problem of confirmation bias may also occur in criminal proceedings. Recently, in the Netherlands, there was quite some tumult about a 
miscarriage of justice in which confirmation bias on the part of police, public prosecution, and even the judge seems to have played a detrimental role. In the pertinent case, the suspect, Kees Borsboom, was convicted in three instances for the rape and murder of a 10-year-old girl in 2000. The conviction heavily leaned on the suspect's confession, even though he had retracted it soon after the crucial interrogation. Eventually, Borsboom was released, once the actual perpetrator, who's DNA was found at the crime scene, confessed. In reaction to the unjust incarceration of Borsboom, the Dutch public prosecution initiated a self-evaluation, resulting in a report of no less than 176 pages (Posthumus, 2005). In this so-called Posthumus report, the author argues that police and public defence developed some kind of tunnel vision, once Borsboom had confessed the murder. Tunnel vision refers here to confirmation bias, in the sense that the parties involved were no longer open to alternatives to the scenario in which Borsboom was the perpetrator. Internationally, a similar example can be found in the infamous Brandon Mayfield case (see Dror, Charlton, \& Péron, 2006).

Apart from incidental miscarriages of justice like in the Borsboom and Mayfield cases, there is some reason to fear that confirmation bias may occur in criminal proceedings based on the structure of criminal proceeding itself. For example, the possibility to incriminate possible third parties is sometimes limited (Findley \& Scott, 2006). Likewise, in the Netherlands, the law dictates that the judge motivates his verdict by naming the evidence that has led him to be convinced of the suspect's guilt. However, nothing is said about the processing of exonerating information, if any. Thus, such exonerating information may simply be discarded implicitly.

Finally, there is also some empirical support for the idea that criminal proceedings can be affected by confirmation bias. For example, Meissner and Kassin (2002) found that police officers, who are convinced that a suspect is lying, cannot easily be brought to change their mind. Similarly, Carlson and Russo (2001) found that jury members tend to interpret information in the light of their previously held convictions, rather than completely objectively. As another example, Ask and Granhag (2005) had participants read one of two versions of a case vignette in which a female psychiatrist is murdered. In one version, the suspect has a clear motive (i.e. jealousy). In the other, there is the serious possibility of another perpetrator than the main suspect. Participants had to rate the incriminating power of various observations made by the police. Whereas the authors had expected that exonerating information (e.g. a witness saw a third person running from the crime scene) would be appreciated more by participants in the latter than by those in the former condition, surprisingly, both groups did not differ in their ratings. Hence, this finding suggests that it is indeed difficult to remain open to alternative scenarios, even if such alternative is presented in a clear-cut manner. Finally, Ask, Rebelius, and Granhag (2008) found that their participants had more faith in DNA, video, and identification evidence if it produced incriminating information, compared with when the outcome of the same procedure was exonerating (see for yet another illustration of tunnel vision in legal contexts, Simon, Snow, \& Read, 2004).

In the present studies, we sought to advance existing knowledge of confirmation bias in criminal proceedings. The main hypothesis was that the criminal procedure inherently fuels confirmation bias. That is, judicial decision-makers are prone to look for guiltconfirming information, rather than exonerating information. To test this idea, we applied the paradigm of Snyder and Swann (1978) to the criminal context. That is, we tested whether participants, who were made knowledgeable about a criminal case, would be more eager to obtain additional incriminating evidence than exonerating information. Kassin, 
Goldstein, and Savitsky (2003) did something similar when they instructed undergraduates that they were to interrogate a suspect. In preparation of this interrogation, participants could choose from a list of 13 questions, some of which were confirming (e.g. 'How did you find the key that was hidden behind the VCR?'), and some were neutral (e.g. 'Do you know anything about the key that was hidden behind the VCR?'). The authors found that participants who were told that in $80 \%$ of the cases, the suspect usually is guilty, selected more guilt-confirming questions ( $v z 3.6$ out of 6 ) than those who were told that on average only $20 \%$ of the suspects are actually guilty in similar cases $(\mathrm{M}=2.6$; see O'Brien, 2009, for a similar study). The present studies aimed beyond the existing knowledge. First, whereas Kassin et al. limited their study to the context of interrogation, the current studies more generally addressed the search for evidence in the context of criminal investigations. Second, participants in the Kassin et al. study could choose between guilt-confirming and neutral questions. In the present studies, however, they had to choose between incriminating and exonerating information, which seems more ecologically valid.

\section{STUDY 1: THE EFFECT OF PRELIMINARY JUDGEMENT ON THE SELECTION OF INVESTIGATION ENDEAVOURS}

A major manifestation of confirmation bias is that one seeks information that confirms a previously made decision (see Nickerson, 1998; Snyder \& Swann, 1978). In this study, it was tested whether this also applies to the context of criminal procedures. The question hence was: is the nature of the selected additional investigations affected by the initial impression of the suspect's guilt. It was hypothesised that participants who believe that the suspect is guilty, subsequently seek more incriminating evidence than participants who believe that he is innocent.

\section{Method}

\section{Participants}

In this study, 79 law students (of which 68 women) participated. The mean age in this sample was 21.0 years $(\mathrm{SD}=1.6$; range: $19-27)$. Participants received course credits in return for completing the procedure.

\section{Measures}

In the three studies presented in this paper, participants were presented with a relatively elaborate case file about a young man who is suspected of physically abusing (i.e. repeatedly beating and kicking) another man. Participants were instructed to determine the suspect's guilt. They were told that they could order additional investigations, if they so desired. For this purpose, they were presented with a list of 20 possible investigations (see Table 1). In fact, half of these investigations were framed in such a way that they were directed at obtaining further evidence against the suspect. The other half was framed so as to obtain exonerating information, by either reducing the strength of existing incriminating evidence, or by obtaining evidence for an alternative scenario.

Two pilot studies were conducted in order to ascertain that incriminating and exonerating endeavours were actually perceived as such by participants, as well as to exclude possible differences in perceived importance between the two types of endeavours. In both pilot studies, participants were given the following information. 
Table 1. Evaluation $(0-100)$ of the direction (incriminating versus exonerating; $n=58$ ) and the importance $(n=40)$ of the 20 investigations

\section{$\longrightarrow$ Direction ${ }^{\dagger}$ Importance}

1. The witness testimony of the victim's girlfriend (Corine de Jong) contains several unexplained contradictions. The mental state of Corine at the time of the incident could be investigated (e.g. had she consumed alcohol?).

3. How good is the relation between the victim and his girlfriend? Is it possible that Corine ordered the beating up of Anton for some reason?

5. Anton has amnesia for the incident. How innocent is he, really? Did he provoke the perpetrator in any way? Anton's behaviour during the incident could be studied further.

7. Anton has amnesia for the incident. How serious is this amnesia? Might Anton be simulating this amnesia? If so, why? This can be investigated.

9. One of the acquaintances of the suspect (Joesef Abdullah) has testified against the suspect. It can be investigated whether Joesef has some unfair motive for such incriminating testimony.

11. It can be investigated whether the police have been conscientious and thorough in their preparation of the various reports (which is unfortunately not always the case).

13. Chief investigators Terschuur and van Dam could be asked to elaborate on their examination of alternative scenarios (e.g. that the suspect is in fact not the actual perpetrator).

15. It could be investigated whether the interrogation of the suspect was conducted properly (e.g. was he informed about his rights, and was there no illegitimate social pressure?).

17. Corine has identified the suspect in a photo line-up. The quality of this line-up could be tested (e.g. were all photographed men physically similar?).

19. It could be investigated medically whether the physical damage suffered by Anton could also have been caused by some other agent than a beating by the suspect.

2. Although the crime scene has been studied, investigators have not yet examined the victim's (Anton de Koning) and his girlfriend's clothes for DNA traces of the suspect. Such investigation could still be initiated.

4. Although the crime scene has been studied, investigators have not yet examined the victim's (Anton) and his girlfriend's clothes for fingerprints of the suspect. Such investigation could still be initiated.

6. The suspect has been interrogated once or twice. The police could be instructed to interrogate him thoroughly once more.

8. Corine has already given her witness testimony. She could be subjected to a special memory-enhancing technique (such as hypnosis, or guided memory retrieval) in order to help her memory and thus obtain a more detailed testimony.

10. Corine has already undergone a photo line-up. Anton could also be subjected to that line-up, in order to explore whether he can identify the suspect (in spite of his amnesia). 
Table 1. (Continued)

\begin{tabular}{lcc}
\hline & Direction $^{\dagger}$ & Importance $^{-}$ \\
\hline $\begin{array}{l}\text { 12. The police could be instructed to conduct a large scale } \\
\text { investigation in the neighbourhood of the crime scene, in order to } \\
\text { recruit more witnesses. }\end{array}$ & 48 & 55 \\
$\begin{array}{l}\text { 14. The police could be ordered to employ local media (e.g. } \\
\text { billboards, newspaper, radio, and TV) to reach potential witnesses. }\end{array}$ & 49 & 59 \\
$\begin{array}{l}\text { 16. The suspect could be evaluated psychologically in order to } \\
\text { estimate the recidivism risk. }\end{array}$ & 59 \\
$\begin{array}{l}\text { 18. The home of the suspect has not been searched. A warrant to } \\
\text { conduct such a search could be produced. }\end{array}$ & 50 \\
$\begin{array}{l}\text { 20. The two acquaintances of the suspect (Joesef and Sjon) could be } \\
\text { interviewed once more. Perhaps, such an additional interview can } \\
\text { yield additional incriminating evidence. }\end{array}$ & 29 & 63 \\
\hline
\end{tabular}

Note. Topics with an odd number were meant to be exonerating, whereas even numbered topics were meant to be incriminating.

'Lower scores indicate that the investigation was perceived as incriminating, whereas higher scores indicate that the investigation was perceived as exonerating.

One evening, Anton de Koning and his girlfriend Corine de Jong are walking in the street. They encounter three boys: Joesef, Sjon, and the man who will become suspect. The latter made a remark about Corine, and Anton swiftly gave a witty reply. They all went their own way. Soon afterwards, the three boys parted from each other. Soon after that, Anton is attacked and abused. The attack has caused physical injury and amnesia. The police think that the suspect, after having said goodbye to Joesef and Sjon, has followed Anton and Corine, and attacked Anton from behind. Imagine that you are the judge who will ultimately determine the suspect's guilt. Already, a lot of evidence is gathered: Corine has identified the suspect from police mug shot series, the suspect had been interrogated, and Anton has been physically examined. It is possible for you to order additional investigations.

In the first pilot study, 58 law students (of which 44 women; mean age: 21.5 years, $\mathrm{SD}=3.9$; range: 19-48) received the following instruction: 'Some of these investigations seem to be aimed at collecting further incriminating evidence, whereas others seem to be exonerating in nature, in that they seek for flaws in the incriminating evidence, or by highlighting alternative scenarios. Please indicate to what extent you find the investigations incrimination of exonerating. Do so by circling the number that corresponds best with your opinion'. Participants rated every investigation on a scale from 0 (incriminating) through 100 (exonerating) with increments of 10.

In the second pilot study, forty law students ( 24 women) with a mean age of 22.4 years $(\mathrm{SD}=3.3$; range: $18-30$ ) were given the following instruction. 'Please indicate how important you think that the investigations listed below, are. Do so by circling the number that corresponds best with your opinion'. Then, participants rated the 20 investigations on a scale from 0 (not at all important) through 100 (very important), with increments of 10 .

The results of the pilot studies are displayed in Table 1. For the intended direction of the investigations (i.e. incriminating versus exonerating), it was tested whether the mean evaluation was significantly lower than 50 (for the incriminating investigations), or higher 
than 50 (for the exonerating investigations). All but three (numbers 8, 12, and 14) investigations differed from $50(p s<0.001)$. Thus, three investigations were perceived as bidirectional. They were retained in the stimulus material, but removed from further analyses. The remaining seven incriminating investigations were judged to be equally important $(\mathrm{M}=63.3, \mathrm{SD}=15.7)$ as the exonerating ones $(\mathrm{M}=61.7, \mathrm{SD}=14.1)$ : $t(39)<$ 1.0. Because we employed 7 incriminating and 10 exonerating investigations, percentages rather than absolute numbers were entered into the analyses (see O'Brien, 2009; Snyder \& Swann, 1978).

The results of these pilot studies ascertain that, while incriminating and exonerating investigations were perceived as such, there was no a priori difference in the perceived importance of the two types of investigations.

The case file used in this study had the same content as the vignette used in the pilot studies, but it was more elaborate. It was based on a study by De Keijser and van Koppen (2007). It was an approximately 20 pages long, fictitious case about a young man in his twenties who is suspect of physical abuse of another man. In short, the suspect was in the street, late at night, with two acquaintances, and so was the later victim, who was en route with his girlfriend. The suspect made a comment about the victim's girlfriend, and the victim replied wittily. Both groups of people went their way, but shortly afterwards, the suspect said goodnight to his two friends and left. He is suspected of having followed the victim and his girlfriend and to have attacked and physically abused the victim. The stimulus material consisted of various files that can also be encountered in real-life criminal dossiers. For example, there was an eyewitness statement of the victim's girlfriend, a statement of the victim, statements of the suspect's acquaintances, a report of the interrogation of the suspect, a report of a line-up procedure in which the victim's girlfriend was confronted with various photographs including one of the suspect, an expert-witness testimony of a neurologist pertaining to the physical complaints of the victim, and psychiatric and criminal dossiers on the suspect. The evidence against the suspect was not overwhelming: the victim's girlfriend identified the suspect in the photo line up, but she was not quite sure.

After having studied the case file, participants were given the following written instruction: 'Now that you have read the case file, you must decide whether the suspect is innocent or guilty. Do so by circling the word "innocent" or "guilty" below".

Next, they were instructed as follows.

Before the final decision on the acquittal or conviction of the suspect is made, you are given the opportunity to initiate additional investigations. Of course, fact finding requires extensive search for evidence. On the other hand, at some point the collection of information inherently comes to an end. Below is a list of possible topics that can be investigated further. Please select those topics that you would like to have investigated. Although there is no maximum, try to be prudent with selecting topics.

The protocol of this study and that of all other studies presented in this paper, was approved by the Ethics Committee at our Institute of Psychology.

\section{Results}

Of the 79 participants, 46 (i.e. 58\%) concluded that the suspect was innocent, whereas the remaining 33 believed that he was guilty. Participants in the former group selected on average 5.4 additional investigations $(\mathrm{SD}=1.7)$, whereas those in the latter group selected 4.6 investigations $(\mathrm{SD}=2.1): t(77)=1.86, p<0.07$. Crucially, of the selected investigations, 
$45 \%$ was incriminating in nature, in the group that had concluded that the suspect was innocent, whereas this percentage was 57, in the group of participants who had decided that the suspect was guilty: $t(77)=2.90, p<0.01$.

\section{Discussion}

The findings suggest that the nature of the information sought, was determined by the preliminary decision, although the quasi-experimental nature of the study precludes firm causal inferences. That is, participants who believed that the suspect was innocent looked for information confirming that he, indeed, was innocent. On the other hand, participants who believed that the suspect was guilty were more interested in investigations aimed at gathering more evidence of guilt. This finding is well in line with research in other decision-making areas, suggesting that people tend to look for information confirming their prior beliefs (see Nickerson, 1998; Snyder \& Swann, 1978). Apparently, the context of criminal proceedings is no exception (see also O'Brien, 2009), although the observed differences were rather modest. The findings stress the importance of delaying conclusions (about guilt) until all relevant information is obtained. Preliminary conclusions may bias subsequent information search, which is detrimental, especially in case of decisions that affect other people's lives, such as criminal convictions.

\section{STUDY 2: INHERENT CONFIRMATION AS A FUNCTION OF EVIDENCE STRENGTH AND CRIME SEVERITY}

In Study 1, participants tended to confirm their preliminary decision. Consequently, participants who believed that the suspect was guilty were more eager to find evidence against the suspect. In the current study, it was tested whether parties tend to favour incriminating investigations over exonerating ones, even if they have not yet concluded that the suspect is guilty. In other words, does the context of criminal proceedings inherently invite an attitude of guilt confirmation (see Findley \& Scott, 2006)? Thus, our first hypothesis was that participants would generally select more incriminating than exonerating investigations.

We further hypothesised that the preference for confirming evidence is influenced by two factors, namely the severity of the crime at hand, and the strength of the evidence already gathered. As to the former, it seems plausible that more severe crimes elicit a stronger desire to punish someone (Bright \& Goodman-Delahunty, 2004; Dror, Peron, Hind, \& Charlton, 2005), and this need for retribution may make decision-makers blind to alternative scenarios, and thus render them more vulnerable to confirmation bias (see De Keijser \& van Koppen, 2007; Posthumus, 2005). As to the latter, it also seems plausible that if there is already an overwhelming amount of evidence against the suspect, it is seductive to wrap the case up by simply finding a final piece of evidence, although it would be worthwhile to attend to exonerating information. As such, an overwhelming amount of evidence may function as a trigger to conclude implicitly that the suspect must be the perpetrator. Although this is not at all problematic if the suspect is indeed the perpetrator, it is unfortunate if he is not. At least, such a process is assumed to have contributed to the aforementioned miscarriage of justice in the Netherlands (Posthumus, 2005). 


\section{Method}

\section{Participants}

The experiment was conducted in a sample of 129 law students (96 women), with a mean age of 24.4 years $(S D=5.1$; range: $20-57$ ). Participants received course credits in return for their enrolment.

\section{Measures and procedure}

In this experiment, four versions of the case file used in Study 1 were employed. In two versions, the evidence was weak. That is, the suspect denied having anything to do with the assault, and the girlfriend identified the suspect in the line-up but declared that she was not sure. In the other two versions, the evidence was strong. That is, the suspect confessed, and the girlfriend reported to be very sure of her identification of the suspect. Apart from the manipulation of the evidence strength, the severity of the assault was also manipulated. In two versions, the assault was simple. The victim suffered from two broken ribs, a superficial flash wound, short-term amnesia, and a mild contusio cerebri. In the other two versions, the assault was aggravated, in that it resulted in neck trauma and consequent irreversible paralysis from the waste down, two broken ribs, severe contusio cerebri with consequent permanent speech problems, and amnesia of unknown duration. Hence, there were four conditions: (1) weak evidence and simple assault $(n=29$; this version was used in Study 1); (2) weak evidence and aggravated assault $(n=33)$; (3) strong evidence and simple assault $(n=36)$; and (4) strong evidence and aggravated assault $(n=31)$. Participants were randomly allocated to these conditions. There were no gender $\left(\chi^{2}[3]=3.0, p=0.39\right)$ or age differences $(F[3]<1.0)$ between the four groups.

After having studied the case file, participants were instructed that they could select additional investigations from the list shown in Table 1 . The instruction was similar to the one in Study 1. It is important to stress that in the current study, participants made no preliminary judgement about the suspect's guilt.

\section{Results}

In all, participants selected $5.0(\mathrm{SD}=2.1)$ investigations. Of these, $37 \%(\mathrm{SD}=22 \%)$ was incriminating. A one sample $t$-test indicated that this was significantly less than $50 \%$ $(t[128]=6.6, p<0.001)$.

The number of selected investigations and the percentage of incriminating ones as a function of experimental condition are presented in Table 2 . The data were analysed with a 2 (weak versus strong evidence) $\times 2$ (simple versus aggravated assault) ANOVA. The

Table 2. Mean number of selected investigations, and the percentage of incriminating investigations (and standard deviations) in the four conditions

\begin{tabular}{lcc}
\hline Condition & $\begin{array}{c}\text { Number of selected } \\
\text { investigations }\end{array}$ & $\begin{array}{c}\text { Percentage of } \\
\text { incriminating investigations }\end{array}$ \\
\hline Weak evidence, simple assault & $4.8(2.0)$ & $30 \%(17 \%)$ \\
Weak evidence, aggravated assault & $4.9(2.5)$ & $34 \%(16 \%)$ \\
Strong evidence, simple assault & $5.0(1.9)$ & $36 \%(26 \%)$ \\
Strong evidence, aggravated assault & $5.1(1.9)$ & $49 \%(22 \%)$ \\
\hline
\end{tabular}


number of selected investigations was not affected by evidence strength, crime severity, or an interaction of these two variables (all $F \mathrm{~s}<1.0$ ).

As to the percentage of incriminating investigations, a main effect of evidence $(F[1]=$ 8.6, $p<0.01)$ and crime severity $(F[1]=5.8, p<0.02)$ occurred, but no interaction effect was observed $(F[1]=1.3, p<0.26)$. That is, both evidence strength and crime severity were positively associated with the selection of incriminating investigations.

\section{Discussion}

Our first hypothesis ( $v z$. participants would generally prefer incriminating investigations over exonerating ones) was rejected. The opposite seemed to be the case. However, as hypothesised, the selection of incriminating investigations increased with both evidence strength and crime severity. The data thus suggest that there is no reason to assume that parties involved in criminal investigations act as if by nature prone to confirm the suspect's guilt. A critical comment is that we employed the percentage of incriminating investigations as the crucial variable. This precludes the possibility of making qualitative judgements about the participants' choices. For example, one might believe that given the evidence in the strong evidence conditions, the selection of even one additional incriminating investigation constitutes confirmation bias. But then, our data do not address such qualitative remarks.

Our finding that participants' selecting of incriminating investigations increased if the evidence already present was stronger, is intuitively plausible. That is, the more one is convinced of the suspect's guilt (based on the amount of evidence), the less open one becomes to alternative scenarios. Although understandable, this evidence driven confirmation proneness is not always rational. Obviously, one can easily argue that especially if the evidence against the suspect already suffices, fact finders should invest some time and effort in alternative scenarios.

Finally, the observation that severe crimes fuel the tendency to confirm the suspect's guilt, is in line with the Dror et al.'s (2005) notion that emotions can get the better of us. Rationally, the severity of the crime should not affect the content of the fact finding process. Perhaps, it can be argued that fact finders try harder to reveal the truth in case of severe crimes, but the content and direction of their activities should not diverge from that in case of milder crimes. In a way, the present data are reminiscent of De Keijser and van Koppen's (2007) notion of the conviction paradox. That is, the severer the crime, the more easily people (including judges and juries) become convinced that the suspect is guilty.

\section{STUDY 3: OBTAINING ADDITIONAL EVIDENCE}

In the previous studies, it was found that making a preliminary judgment about the suspect's guilt is associated with the subsequent search for information (Study 1), and that whereas generally there was no preference for incriminating information, evidence strength and crime severity fuelled the selection of guilt-confirming investigations (Study 2). In the present study, we sought to explore the effect of actually obtaining the selected information on the ultimate decision about the suspect's guilt. Evidently, we hypothesised that obtaining incriminating information would increase participants' tendency to convict the suspect. However, it must be acknowledged that in real-life, it may not be that simple. For example, engaging in a guilt-confirming investigation (e.g. conducting an extra interroga- 
tion; Inbau, Reid, Buckley, \& Jayne, 2001) does not necessarily result in obtaining the information sought (e.g. a confession). In other words, every investigation can either result in obtaining the pertinent information, or not. Therefore, we created several conditions, in which the results of the additional investigations differed. It was expected that the percentage of selected incriminating investigations would be positively associated with conviction rate, if the outcome of the confirming investigations was positive.

\section{Method}

\section{Participants}

In this study, 182 law students participated (132 women). The mean age in this sample was 21.5 years $(\mathrm{SD}=3.3$; range: $19-52$ ). There were five conditions, based on the possibility to obtain additional information and the differential outcomes of the investigations. There were no gender $\left(\chi^{2}[4]=3.8, p=0.44\right)$, or age differences $(F[4]<1.0)$ between these five groups. All participants were tested individually, and received course credits in return for their participation.

\section{Measures and procedure}

All participants were given the strong-evidence-aggravated-assault version of the case file also used in Study 2. After reading this file, 41 participants were asked to indicate whether they would convict or acquit the suspect, based on the information present in the file. These 41 participants constituted the control group that would deliver the conviction rate in absence of any additional investigations. The remaining participants were given the list of possible investigations also used in the previous studies. They were instructed that they could initiate additional investigations if they so desired, before deciding on the suspect's guilt. After they had indicated which additional information they would like to obtain, the experiment leader handed over a written outcome of every selected investigation. Based on this outcome, there were four conditions.

In the positive condition $(n=22)$ all investigations delivered a positive outcome. Hence, both incriminating investigations (e.g. number 2) and exonerating ones (e.g. number 3) yielded the expected result. For number 2, the participant would be given a piece of paper stating: 'In the additional investigation, the forensic investigators indeed found traces of the suspect's DNA on the clothes of Anton and Corine'. The solution to investigation number 3 was: 'The additional investigation has delivered reason to conclude that the relation between Anton and Corine had turned bad, and that Corine may well have ordered a physical assault on Anton'.

In the negative condition $(n=42)$, all investigations failed to yield the expected result. Here, the solution to investigation number 2 was: 'In the additional investigation, the forensic investigators did not find any traces of the suspect's DNA on the clothes of Anton and Corine'. The solution to number 3 was: 'The additional investigation has delivered no reason to conclude that the relation between Anton and Corine had turned bad, nor that Corine would have ordered a physical assault on Anton'.

In the incriminating condition $(n=43)$, guilt-confirming investigations yielded the expected result, but exonerating investigative endeavours failed.

Finally, in the exonerating condition $(n=34)$, incriminating investigations yielded no positive results, whereas exonerating investigations did yield the expected results. 
After obtaining the outcomes to the requested investigations, and having had as much time as desired to contemplate, participants were asked to indicate whether they would convict or acquit the suspect.

\section{Results}

In the four conditions in which it was possible to select additional topics $(n=141)$, participants selected on average 3.7 investigations $(\mathrm{SD}=1.6$ ), of which $31 \%$ was guilt-confirming ( $\mathrm{SD}=26 \%$ ). The four groups did not differ with regard to the number of selected investigations $(F[3]=1.1, p=0.35)$, nor regarding the percentage of incriminating investigations $(F[3]<1.0)$.

The overall conviction rate was $83 \%$. Conviction rates in the various conditions were: $95 \%$ in the control condition, $77 \%$ in the positive condition, $83 \%$ in the negative condition, $100 \%$ in the incriminating condition, and $49 \%$ in the exonerating condition: $\chi^{2}(4)=40.4$, $p<0.001$.

Next, we compared the percentages of selected confirming investigations between participants who convicted the suspect and those who acquitted him. Evidently, in this analysis, the control condition was excluded. Of the topics chosen by participants who subsequently chose to convict the suspect $(n=109), 33 \%(\mathrm{SD}=27 \%)$ was guiltconfirming. This percentage was only $22 \%(\mathrm{SD}=18 \%)$ for participants who acquitted the suspect $(n=29): t(136)=2.5, p=0.01$. Finally, we predicted the ultimate judgement (conviction versus acquittal) with condition and the percentage of chosen confirming investigations. In this logistic regression analysis, both condition (Wald $=5.3, p=0.02$ ) and the percentage of confirming investigations (Wald $=4.1, p=0.04$ ) contributed significantly to the prediction of convictions.

Figure 1 presents the percentage of selected confirming investigations as a function of condition and the ultimate decision (conviction versus acquittal). As can be seen, choosing confirmatory investigations was primarily associated with conviction rate in the positive and in the exonerating conditions. In de negative condition, convicters and acquitters did not differ in their tendency to select confirming investigations. In the incriminating condition, all participants chose to convict the suspect.

\section{Discussion}

As in Study 2, participants did not display a preference for guilt-confirming investigations (mean percentage being $31 \%$ ). Importantly, however, choosing confirmatory topics was associated with conviction rate. This conclusion can be drawn from the finding that those participants who convicted the suspect had chosen more confirming investigations compared to their acquitting peers. What is especially striking is that the selection of confirming investigations was associated with conviction rate in the exonerating condition. Note that in this condition, every endorsed confirmatory investigation yielded a negative result. Hence, one might have expected that in this condition, the selection of confirmatory investigations would have driven participants to acquit the suspect, because every confirming investigation failed to yield additional incriminating evidence. This paradoxical finding is reminiscent of that reported by Snyder and Swann (1978), being that the mere selection of confirming investigations may suffice to convince observers, even if the investigations do not actually yield the expected confirming evidence. 


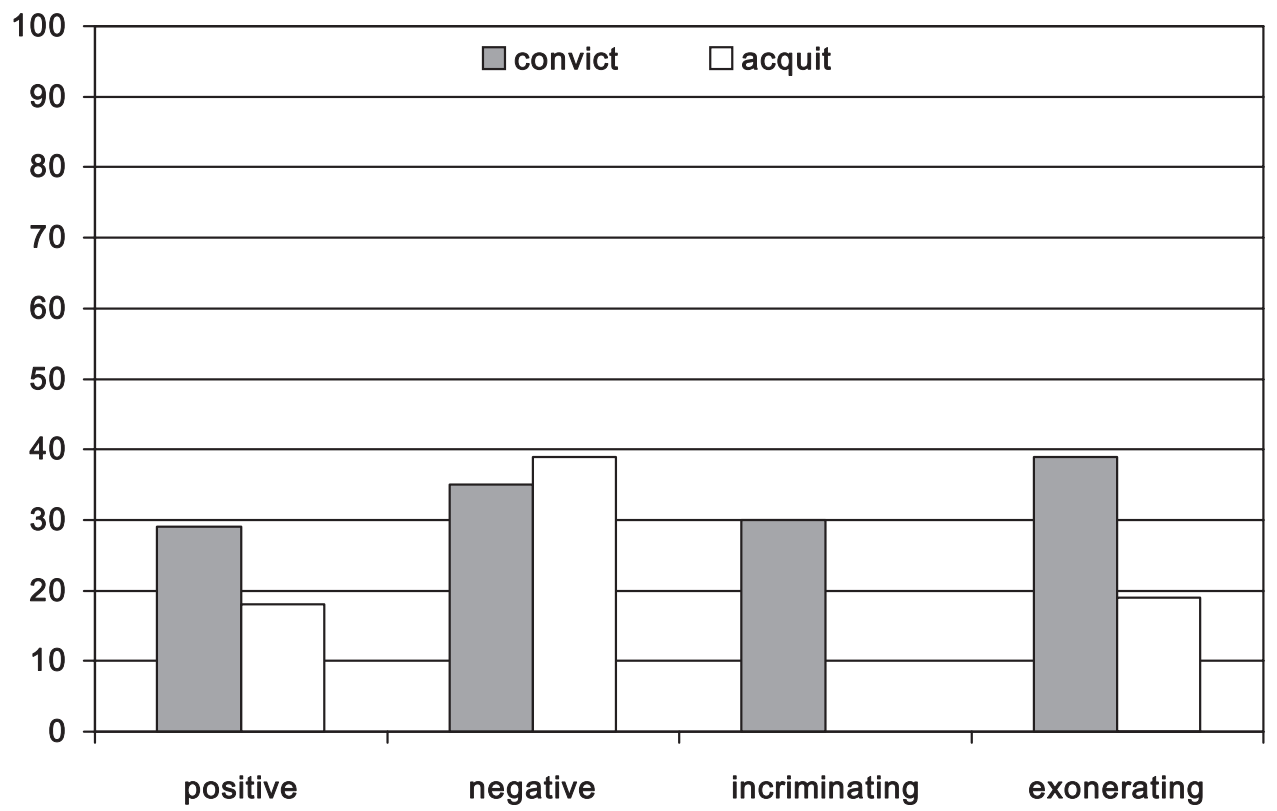

Figure 1. Percentage of selected incriminating investigations as a function of condition and ultimate decision (conviction versus acquittal).

One obvious limitation of this study is the high base rate of convictions in the control group (i.e. 95\%). This ceiling effect remains unexplained, but evidently, it would have been better if the base rate of convictions were approximately 50\%. This skewness resulted in small subgroups that made comparisons between convicters and acquitters less reliable-or even impossible in the incriminating condition. Another critique is that especially the positive condition might be somewhat artificial. Particularly, one can wonder whether it is possible to simultaneously confirm all hypotheses implicated in the endeavours listed in Table 1. However, fortunately, none of the participants in that condition chose to select more than seven investigations.

\section{GENERAL DISCUSSION}

The present studies set out to explore a specific manifestation of confirmation bias (or, if one will, tunnel vision) in the context of evidence gathering in criminal proceedings. That is, it was hypothesised that individuals who are faced with the question whether a suspect is guilty, are more likely to be interested in guilt-confirming investigations than in exonerating investigations. The findings did not generally support this idea. In Study 1, participants who were convinced of the suspect's guilt favoured incriminating investigations (57\%), but those who were convinced that he was innocent did not $(45 \%)$. Hence, this study yielded support for the idea that participants' information search was guided by their prior conviction. However, in absence of a verbalized prior conviction, only $37 \%$ of the selected investigations by participants in Study 2 was guilt-confirming. Interestingly, this percentage was fuelled by both the strength of the evidence already present and the severity of the crime. Finally, Study 3 delivered results suggesting that the selection of incriminat- 
ing investigations was associated with conviction rates, regardless whether the investigations yielded the expected outcome or not.

Evidently, the studies are limited in various ways. First, they relied on law students, while in many legal systems, the fact finding is conducted by or under supervision of professional judges. Therefore, the question arises to which extent the findings can be extrapolated to the decision making by professionals. We like to argue that the differences between professional judges and lay people are not impressive when it comes to the performance in fact finding (see Kalven \& Zeisel, 1966; see also Rassin, 2010, for an illustration of similar cognitive processes in students, police officers, and legal professionals). After all, fact finding is not a judicial but an empirical activity. Further, whereas the validity of the present findings for professional judges can be questioned, it must be recognised that in several systems, it are lay people who are burdened with the determination of the suspect's guilt.

Another limitation lies in the design of the studies. That is, participants were presented with 20 (of which 17 were included in the analyses) topics for further investigation. In real-life, however, fact finders are not presented with such explicit alternatives. They have to conjure them up themselves. Under those naturalistic circumstances, the ultimate production and selection of further investigations may be different from that observed in the current studies. Likewise, the magnitude of the confirmation bias may well exceed that observed in the current studies, because our participants were presented with all possible investigations simultaneously, whereas in real-life the different routes are likely to present themselves sequentially. It is established that confirmation bias is stronger in case of sequential information processing (Jonas, Schulz-Hardt, Frey, \& Thelen, 2001). Further, it must be acknowledged that some of the endeavours listed in Table 1 might be considered a bit academic, and not so realistic.

Meanwhile, the findings cast some doubt on the assumption that the confirmation bias lurks in legal decision making (see Kerstholt \& Eikelboom, 2007; Schünemann \& Bandilla, 1989). That is, leaving one exception, it can be concluded that participants did not favour incriminating evidence over exonerating evidence. If anything, the opposite seemed to be true. Hence, the data do not support the claim that legal fact finders are prone to seek evidence of the suspect's guilt. Interestingly, should a preference for incriminating evidence occur, O'Brien (2009) recently argued that such confirmation bias can be counteracted by thinking of reasons why the suspect may in fact be innocent. Snook and Cullen (2008) even argued that tunnel vision is not necessarily detrimental. In the words of these authors: "policy recommendations to eliminate wrongful convictions by eradicating mental viruses are not based on any hard facts ... Perhaps tunnel vision is used in every case, but only a very small percentage of these result in wrongful convictions' (p. 92). However, these authors define tunnel vision not only as confirmation bias, but as a compilation of confirmation bias, and decision making heuristics such as satisficing and elimination by aspect. And whereas Snook and Cullen are right in arguing that the sensitivity and selectivity of tunnel vision for wrongful convictions is unknown, it can well be argued that confirmation bias in itself is undesired.

Of particular interest is the finding in Study 3, indicating that by displaying interest in guilt-confirming investigation routes, fact finders actually appear to create non-existent evidence for the suspect's guilt. That is, even if the search for incriminating evidence did not yield the expected outcome, the mere selection of such investigations was associated with conviction rates. Logically, the absence of incriminating evidence additionally searched can be interpreted as an indication of innocence. But admittedly, the exonerating 
power of absent evidence is not always recognised (see Findley \& Scott, 2006; Jenkins \& Schuller, 2007; McKenzie, Lee, \& Chen, 2002). More likely, it is argued that absence of evidence is not evidence of absence (see Jervis, 2006). It should be acknowledged though, that it is inherent in the paradigm of Study 3, that in the exonerating condition, increased selection of (failing) searches for incriminating evidence equals a decrease in the number of (succeeding) searches for exonerating evidence.

In sum, whereas the present findings yield no support for the idea that legal fact finders are by definition more interested in guilt confirmation than in exoneration, they do illustrate that the selection of incriminating versus exonerating investigations is guided by prior convictions, that evidence strength and crime severity also affect the preference for incriminating investigations, and that the actual selection of incriminating investigations is associated with higher conviction rates, even if the outcome of the investigations is negative. Evidently, such detrimental effects deserve further attention of scientists and practicing lawyers.

\section{REFERENCES}

Ask, K., \& Granhag, P. A. (2005). Motivational sources of confirmation bias in criminal investigations: The need for cognitive closure. Journal of Investigative Psychology and Offender Profiling, 2, 43-63.

Ask, K., Rebelius, A., \& Granhag, P. A. (2008). The 'elasticity' of evidence: A moderator of investigator bias. Applied Cognitive Psychology, 22, 1245-1259.

Bright, D. A., \& Goodman-Delahunty, J. (2004). The influence of gruesome verbal evidence on mock juror verdicts. Psychiatry, Psychology and Law, 11, 154-166.

Carlson, K. A., \& Russo, J. E. (2001). Biased interpretation of evidence by mock jurors. Journal of Experimental Psychology: Applied, 7, 91-103.

De Keijser, J. W., \& van Koppen, P. J. (2007). Paradoxes of proof and punishment: Psychological pitfalls in judicial decision making. Legal and Criminological Psychology, 12, 189-205.

Dror, I. E., Péron, A. E., Hind, S. L., \& Charlton, D. (2005). When emotions get the better of us: The effect of contextual top-down processing on matching fingerprints. Applied Cognitive Psychology, 19, 799-809.

Dror, I. E., Charlton, D., \& Péron, A. E. (2006). Contextual information renders experts vulnerable to making erroneous identifications. Forensic Science International, 156, 74-78.

Findley, K. A., \& Scott, M. S. (2006). The multiple dimensions of tunnel vision in criminal cases. Wisconsin Law Review, 2, 291-397.

Inbau, F. E., Reid, J. E., Buckley, J. P., \& Jayne, B. C. (2001). Criminal interrogation and confessions. Gaithersburg: Aspen Publishers.

Jenkins, G., \& Schuller, R. A. (2007). The impact of negative forensic evidence on mock juror's perceptions of a trial of drug-facilitated sexual assault. Law and Human Behavior, 31, 369-380.

Jervis, R. (2006). Reports, politics, and intelligence failures: The case of Iraq. The Journal of Strategic Studies, 29, 3-52.

Jonas, E., Schulz-Hardt, S., Frey, D., \& Thelen, N. (2001). Confirmation bias in sequential information search after preliminary decisions: An expansion of dissonance theoretical research on selective exposure to information. Journal of Personality and Social Psychology, 80, 557-571.

Kalven, H., \& Zeisel, H. (1966). The American jury. Boston: Little brown.

Kassin, S. M. (2005). On the psychology of confessions: Does innocence put innocents at risk? American Psychologist, 60, 215-228.

Kassin, S. M., Goldstein, C. C., \& Savitsky, K. (2003). Behavioral confirmation in the interrogation room: On the dangers of presuming guilt. Law and Human Behavior, 27, 187-203.

Kerstholt, J. H., \& Eikelboom, A. R. (2007). Effects of prior interpretation on situation assessment in crime analysis. Journal of Behavioral Decision Making, 20, 455-465. 
Lord, C. G., Ross, L., \& Lepper, M. R. (1979) Biased assimilation and attitude polarization: The effects of prior theories on subsequently considered evidence. Journal of Personality and Social Psychology, 37, 2098-2109.

McKenzie, C. R. M., Lee, S. M., \& Chen, K. K. (2002). When negative evidence increases confidence: Change in belief after hearing two sides of a dispute. Journal of Behavioral Decision Making, 15, 1-18.

Meissner, C. A., \& Kassin, S. M. (2002). 'He's guilty!': Investigator bias in judgments of truth and deception. Law and Human Behavior, 26, 469-480.

Nickerson, R. S. (1998). Confirmation bias: A ubiquitous phenomenon in many guises. Review of General Psychology, 2, 175-220.

O'Brien, B. (2009). Prime suspect: An examination of factors that aggravate and counteract confirmation bias in criminal investigations. Psychology, Public policy, and Law, 15, 315-334.

Posthumus, F. (2005). Evaluatieonderzoek in de Schiedammer parkmoord [Evaluation in the Schiedam park murder]. Den Haag: Openbaar ministerie.

Rassin, E. (2010). Blindness to alternative scenarios in evidence evaluation. Journal of Investigative Psychology and Offender Profiling, 7, 153-163.

Schünemann, B., \& Bandilla, W. (1989). Perseverance in courtroom decisions. In H. Wegener, F. Lösel, \& J. Haisch (Eds.), Criminal behavior and the justice system: Psychological perspectives (pp. 181-192). New York: Springer.

Simon, D., Snow, C. J., \& Read, S. J. (2004). The redux of cognitive consistency theories: Evidence judgments by constraint satisfaction. Journal of Personality and Social Psychology, 86, 814-837.

Snook, B., \& Cullen, R. M. (2008). Bounded rationality and criminal investigations: Has tunnel vision been wrongfully convicted? In D. K. Rossmo (Ed.), Criminal investigative failures (pp. 71-98). Boca Raton: CRC press, Taylor \& Francis Group.

Snyder, M., \& Swann, W. B. (1978). Hypothesis-testing processes in social interaction. Journal of Personality and Social Psychology, 36, 1202-1212.

Wason, P. C. (1968). Reasoning about a rule. Quarterly Journal of Experimental Psychology, 20, 273-281. 